\title{
A EXTRAJUDICIALIZAÇÃO COMO FERRAMENTA DE EFETIVIDADE DA JUSTIÇA
}

\author{
Naurican Ludovico Lacerda ${ }^{1}$ \\ Bianca Castellar de Faria ${ }^{2}$
}

\begin{abstract}
Resumo
A efetividade da justiça, necessária ao Estado Democrático de Direito, depende de substrato material para sua efetiva implementação. A existência de uma prestação jurisdicional célere e de menor custo possível à sociedade são elementos essenciais desse substrato, juntos com a independência dos magistrados e outros atributos dos quais se reveste, ao menos idealmente, nosso Poder Judiciário. O presente trabalho visa a demonstrar que as serventias extrajudiciais são ferramentas essenciais à efetividade da justiça, porque aumentam não somente a celeridade processual, como reduzem custos do Poder Judiciário, além de trazer receitas de parcela de seus emolumentos.
\end{abstract}

Palavras-chave: celeridade processual; economicidade processual; serventias extrajudiciais; ferramenta; Judiciário.

\section{EXTRAJUDICIALIZATION AS A TOOL FOR THE EFFECTIVENESS OF JUSTICE}

\begin{abstract}
The effectiveness of justice, necessary for the Democratic Rule of Law, depends on the material substrate for its effective implementation. The existence of a swift judicial provision and at the lowest possible cost to society are essential elements of this substrate, together with the independence of judges and other attributes which, at least ideally, our Judiciary Power is covered by. The present work aims to demonstrate that extrajudicial services are essential tools for the effectiveness of justice, because they not only increase procedural speed, but also reduce costs for the Judiciary, in addition to bringing revenue.
\end{abstract}

Keywords: procedural speed; procedural economy; extrajudiciary services; tool; Judiciary.

\section{INTRODUÇÃO}

O presente artigo tem como objeto demonstrar a importância de se utilizar as serventias extrajudiciais como ferramenta de efetividade da justiça. Entende-se como

\footnotetext{
${ }^{1}$ Tabelião de Protesto e Registrador; bacharel em Direito pela Universidade de Brasília; mestre em Direito Constitucional pelo IDP-Brasília; doutorando em Direito pela Univali-SC em dupla titulação com a Delaware Law School. Email: naurican@gmail.com.

${ }^{2}$ Registradora de Imóveis de Joinville-SC; vice-presidente do ONR; diretora de ensino do Colégio Registral Imobiliário de Santa Catarina; bacharel em Direito pela Universidade Federal do Rio Grande do Sul; mestre em Direito Público pela Universidade Federal do Rio Grande do Sul; doutoranda em Direito pela UnivaliSC em dupla titulação com a Delaware Law School.
} 
efetividade da justiça a obtenção de resultado prático, em tempo razoável e a um custo adequado para a sociedade como um todo. De nada adianta ser titular de determinado direito e nunca poder usufrui-lo em razão da excessiva demora em fazer valer o seu direito.

O seu objetivo é apontar a necessidade e a utilidade de se utilizar as serventias extrajudiciais para tornar mais célere e de menor custo o processo judicial e apontar algumas experiências de sucesso que podem indicar possíveis meios de redução da demora processual e de seu elevado custo. O método utilizado é o indutivo, partindo de experiências existentes como indícios de possibilidade de ampliação de casos específicos para demonstrar a validade do modelo de delegação aos serviços notariais e de registro.

Para tanto, o artigo está dividido em 3 partes. Na primeira parte demonstra-se o excessivo tempo para a prestação jurisdicional, implicando falta de efetividade desse serviço essencial.

Na segunda parte, faz-se uma análise do excessivo custo da prestação jurisdicional brasileira, com dados extraídos principalmente do relatório anual denominado Justiça em Números, do Conselho Nacional de Justiça.

$\mathrm{Na}$ terceira parte, apresentam-se exemplos de extrajudicialização cujas implantações parecem ter sido bem-sucedidas, principalmente nos quesitos tempo e custo para o jurisdicionado e para a sociedade. Entende-se como extrajudicialização a retirada de procedimentos do Poder Judiciário e a sua delegação para serventias extrajudiciais.

\section{DO TEMPO NECESSÁRIO À PRESTAÇÃO JURISDICIONAL NO BRASIL}

A prestação jurisdicional, como serviço posto para a sociedade brasileira e tendo como objetivo servir à sociedade (significado direto do etmo do vocábulo serviço), precisa sempre se ajustar às necessidades dessa sociedade, que estão em constante mudança. No momento que determinado instituto ou serviço deixa de ser útil ou tem sua utilidade diminuída, a sua própria importância decresce.

O Poder Judiciário é evidentemente fundamental ao saudável funcionamento do 
Estado Democrático de Direito. Não há como vislumbrar uma sociedade democrática sem uma Justiça forte, atuante e com elevada legitimidade. Entretanto, a legitimidade desse poder perante a sociedade depende de dois fatores básicos da atividade humana: o que ele entrega de resultado e o custo que ele representa. A relação custo/benefício não se apresenta como muito favorável nos serviços jurisdicionais: dados do "Justiça em Números", relatório estatístico realizado anualmente pelo Conselho Nacional de Justiça, apontam para um elevado custo do Poder Judiciário, da ordem de cem bilhões de reais, e de um grande lapso temporal para a solução de demandas, conforme se analisará mais adiante.

A Emenda Constitucional $n^{\circ} 45 / 2004$ incluiu o direito à duração razoável do processo no inciso LXXVIII no rol de direitos e garantias fundamentais do $\operatorname{artigo} 5^{\circ}$ da Constituição Federal:

LXXVIII - a todos, no âmbito judicial e administrativo, são assegurados a razoável duração do processo e os meios que garantam a celeridade de sua tramitação.

A morosidade da prestação jurisdicional não somente é tema que permeia o senso comum, foi um dos fundamentos da EC 45/2004, Reforma do Poder Judiciário, como também está demonstrada em levantamentos anuais realizados pelo Conselho Nacional de Justiça, em relatórios denominados "Justiça em Números" (CNJ, 2021). Compulsando o tempo médio de baixa processual do último relatório Justiça em Números 2020, verificamos que os lapsos temporais são grandes, mormente na fase de execução, conforme se verifica no quadro a seguir extraído do relatório:

Figura 1 - Tempo médio do processo baixado pelo Poder Judiciário em 2016. 


\section{Tempo médio do processo baixado no Poder Judiciário}

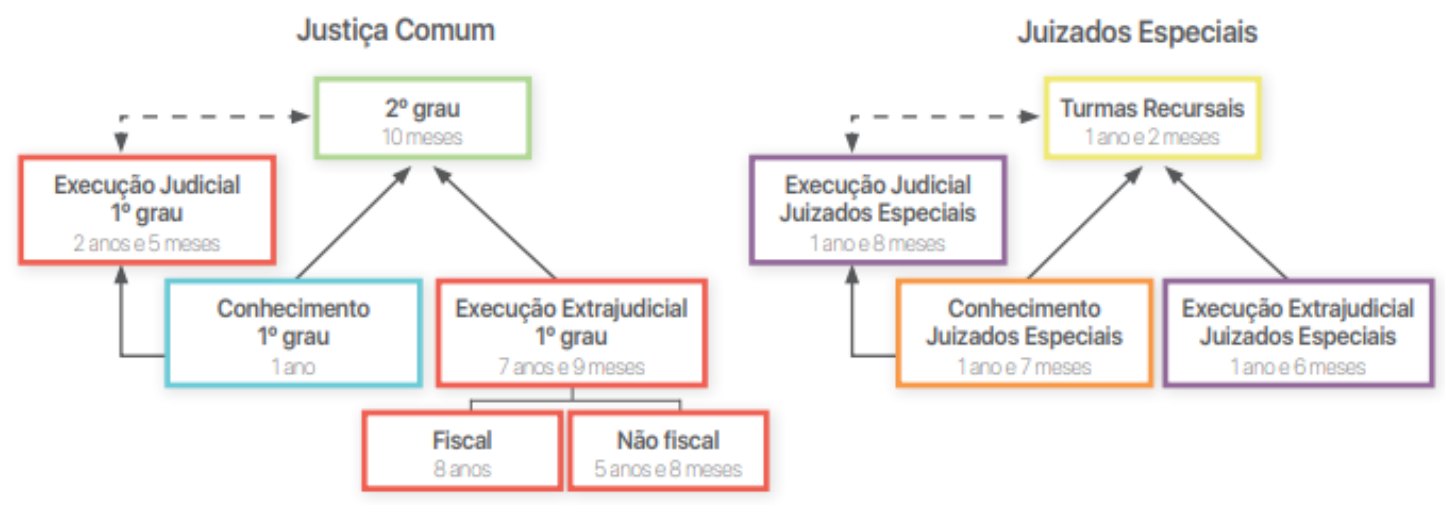

Fonte: CNJ. Relatório Justiça em Números 2020. Disponível em: https://www.cnj.jus.br/wpcontent/uploads/2019/08/b60a659e5d5cb79337945c1dd137496c.pdf

Está expresso na ilustração acima que, na Justiça Comum, a execução de título extrajudicial se prolonga por sete anos e nove meses (como evidência que este indicador não está melhorando, temos que o prazo era de seis anos no mesmo relatório referente ao ano 2016) e a execução judicial, que segue a fase de conhecimento de um processo, demora mais que o dobro do tempo da sentença - um ano para a decisão de conhecimento de $1^{\circ}$ grau e dois anos e cinco meses para a sua execução chegar a termo. Essa constatação chega a ser surpreendente, pois se imagina que a questão mais elaborada em uma demanda é exatamente a obtenção de uma sentença de conhecimento, ato intimamente ligado à atuação do magistrado. Entretanto, a jurisdição em sua acepção mais direta não parece ser a dificuldade que provoca a demora processual, mas os atos burocráticos necessários a sua execução.

A duração excessiva dos processos judiciais e seu custo para sociedade podem transformar o acesso à Justiça em utopia e representar uma distorção sistêmica do nosso ordenamento jurídico ao criar um fardo tanto maior quanto menor for a capacidade econômica das partes. É certo que toda a sociedade e o ambiente negocial sofrem com um índice elevado 
de ineficiência da jurisdição, mas é a camada de menor poder aquisitivo a que mais tem a perder. Grandes corporações possuem lastro para suportar longas demandas e aguardar muito tempo pelo seu desfecho, mas é de se supor que a população das camadas mais frágeis possui menor resiliência e urgência maior nos deslindes judiciais. LAZZARI, SAVARIS E PORENA (2014, p.1291) mencionam que corporações tendem a ter maiores condições de suportar tais ônus do que demandantes individuais.

Boaventura de Sousa Santos (1986, p.19) advoga que os obstáculos ao acesso à Justiça podem ser de três tipos: econômicos, sociais e culturais. Ele defende que especialmente a lentidão processual é mais gravosa para a parcela economicamente mais frágil da população.

CUNHA, KLIN E PESSOA (2011), em nota técnica do Ipea, demonstram que as execuções fiscais da Procuradoria Geral da Fazenda Nacional tramitam por quase uma década antes de seu encerramento (nove anos e nove meses). Entre suas conclusões estão as de que o valor médio cobrado do contribuinte é de $\mathrm{R} \$ 26.303,25$; que a citação é um enorme gargalo inicial; e que em 36,3\% dos casos não há qualquer citação válida. Apesar desses dados serem de 2011, conforme dados já trazidos do CNJ, o quadro ainda se mantém, com o prazo de oito anos para os executivos fiscais.

Alguns exemplos de dificuldades operacionais e que, potencialmente, poderiam ser suplantadas pela delegação das atribuições a terceiros com fé pública encontramos no texto da nota (CUNHA, KLIN E PESSOA, 2011, p.7), transcritas a seguir:

Pouco mais de três quintos dos processos de execução fiscal promovidos pela PGFN vencem a etapa de citação. Destes, $22,7 \%$ conduzem à penhora, mas somente $17,2 \%$ das penhoras resultam em leilão. Nas entrevistas realizadas ao longo da pesquisa, os diretores de secretaria e serventuários da Justiça responsáveis pela etapa do leilão demonstraram profundo desalento com a complexidade dos atos administrativos e judiciais necessários à realização de um leilão, que são extraordinariamente burocráticos, demandam muito trabalho e são de pouca efetividade. Como resultado, muitas das varas da Justiça Federal implantadas nos últimos cinco anos jamais realizaram qualquer pregão. 
Como se vê, tratam-se de dificuldades operacionais que poderiam ser suplantadas pela atuação das serventias extrajudiciais. Os atos de intimação para pagamento de débitos é ato especializado realizado mormente pelos tabelionatos de protesto, conforme dispõe a Lei 8.935/1994,

O quadro apontado por CUNHA, KLIN E PESSOA (2011, p.10) é de baixa efetividade de alguns atos processuais que claramente poderiam ser atribuídos aos serviços notariais e registrais:

Quanto à taxa de sucesso dos meios empregados para a citação, pode-se afirmar que $61,9 \%$ das tentativas de citação por carta registrada (aviso de recebimento - AR) são exitosas, contra $51,7 \%$ das tentativas de citação por oficial de justiça e $44 \%$ das tentativas de citação por edital. Contrariamente ao senso comum, a taxa de sucesso das tentativas de citação por oficial de justiça é significativamente pior do que a das tentativas de citação por AR. Igualmente surpreendente é que a taxa de sucesso das tentativas de citação por edital seja de apenas 44\%. Como o emprego destes instrumentos só não é exitoso quando este contém algum erro ou imprecisão e precisa ser republicado, uma taxa de sucesso tão baixa indica que a quantidade de equívocos na publicação é bastante expressiva.

Seria razoável pensar que as dificuldades da cobrança de débitos fiscais teriam como um dos principais motivos a possibilidade de recursos por parte dos devedores, mas esse não é o caso, pois o resultado obtido pela irresignação dos executados é, em média, muito pequeno CUNHA, KLIN E PESSOA (2011, p.9):

O número de devedores que apresentam defesa é baixo e a taxa de
sucesso é ainda pior. Somente $3,8 \%$ dos executados apresentam objeção
de preexecutividade, as quais são julgadas favoravelmente ao devedor em
$0,5 \%$ dos casos. Já os $6,5 \%$ de executados que apresentam embargos
obtêm ganho de causa em $0,9 \%$ dos casos. Logo, a taxa de sucesso do
devedor nas objeções de preexecutividade é de $8,2 \%$, enquanto nos
embargos é de $14,3 \%$.

Ao final, o levantamento realizado no âmbito do IPEA chegou a um tempo médio de execução fiscal de 9 anos, 9 meses e 16 dias, a um custo médio por processo de R $\$ 5.606,67$, e, em somente em 25,8\% dos processos há o pagamento integral da dívida. Considerando o valor de médio de cada execução já citado, R\$26.303,25 CUNHA, KLIN E PESSOA (2011, p.5), temos que o valor médio recuperado é de $\mathrm{R} \$ 6.786,24$ (produto do valor médio de cada execução pela sua taxa de sucesso). Deduzindo-se o custo individual, temos um retorno médio de $\mathrm{R} \$ 1.179,57$, que representa $4,5 \%$ do valor da execução. 
Em síntese: após nove anos e nove meses, a PGFN consegue recuperar $4,5 \%{ }^{3}$ daquilo que cobra judicialmente do contribuinte, além de representar um elevado fardo aos tribunais pelo grande número de processos.

\section{DO CUSTO DO PODER JUDICIÁRIO}

As despesas do Poder Judiciário brasileiro estão entre as mais altas entre os estados federados de todo o hemisfério ocidental, representando, de acordo com Luciano Da Ros (2015, p.4), um percentual do Produto Interno Bruto brasileiro equivalente a mais de nove vezes o percentual do Poder Judiciário estadunidense, $1,30 \%$ no caso brasileiro, contra $0,14 \%$.

\footnotetext{
${ }^{3}$ Esse valor desconsidera os adimplementos parciais que não constam na nota técnica.
} 
Figura 2. Despesa do Poder Judiciário como (\%) percentual do Produto Interno Bruto, países selecionados

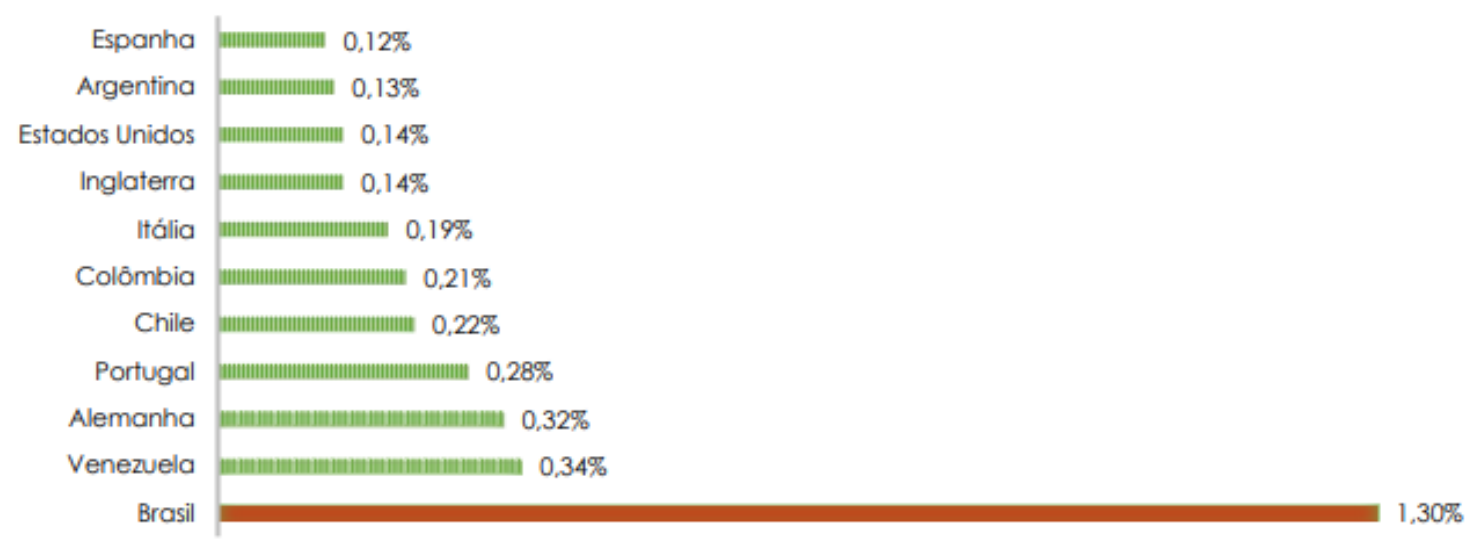

Fonte: Da ROS, 2015, p.4

Não somente a lentidão na resolução de processos judiciais é questão relevante, mas o crescente custo do Poder Judiciário para a sociedade. A cada ano, além das despesas aumentarem, temos a manutenção de um grande déficit entre o que se arrecada com as custas judiciais e aquilo que é dispendido.

Esse o quadro também é comprovado por sucessivos levantamentos realizados pelo Conselho Nacional de Justiça, também no âmbito do relatório anual "Justiça em Números" (CNJ,2020). No ano de 2019, as despesas totais do Poder Judiciário somaram R \$ 100,2 bilhões. o que representou crescimento de $0,4 \%$ em relação ao último ano e uma média de 3,9\% reais ao ano desde 2011. Conforme se vê na figura abaixo, extraída do relatório do CNJ, as despesas cresceram $\mathrm{R} \$ 33,1$ bilhões em dez anos, em termos reais considerando-se o IPCA. Isso representou um aumento real de 49,2\% em dez anos. O aumento per capita também é preocupante. Em 2009, o Poder Judiciário custava a cada brasileiro R $\$ 351,52$. Passados dez anos, seu custo atingiu R $\$ 479,16$, valores deflacionados utilizando-se o IPC-A, um aumento real superior a $36 \%$ em apenas dez anos. 
Figura 3: Série histórica das despesas por habitante

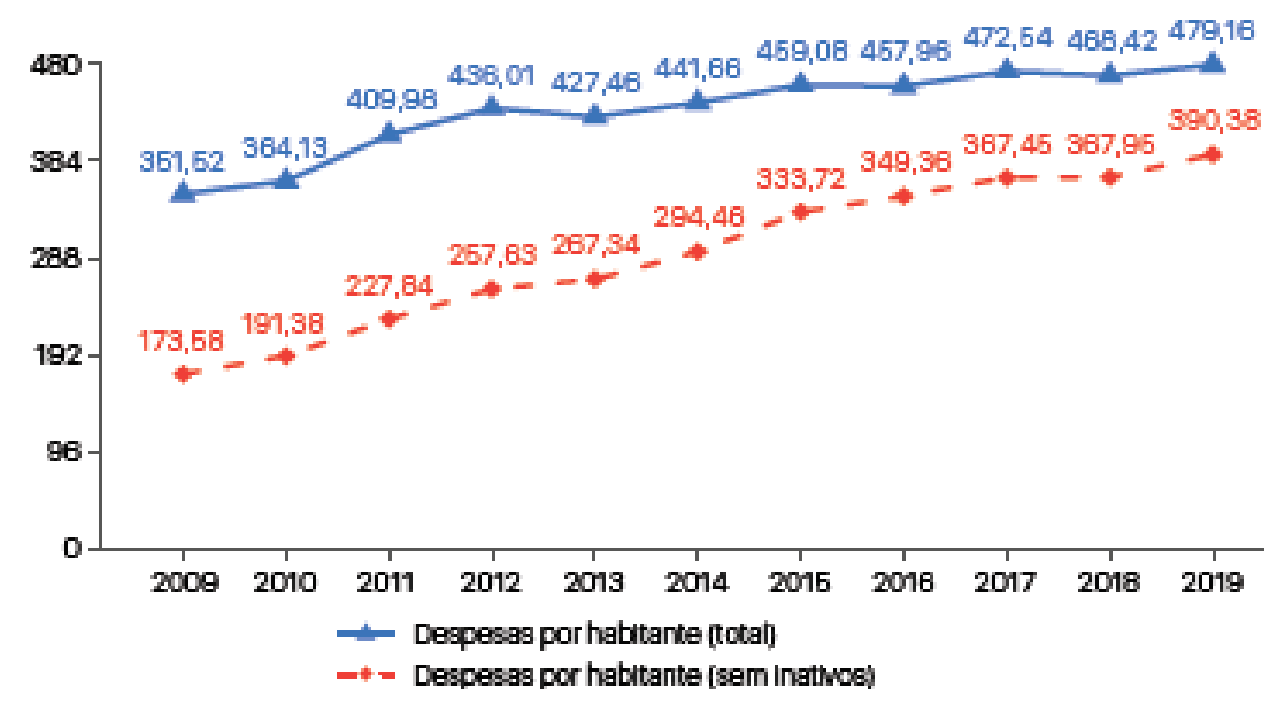

Fonte: CNJ. Relatório Justiça em Números 2020. Disponível em: https://www.cnj.jus.br/wpcontent/uploads/2019/08/b60a659e5d5cb79337945c1dd137496c.pdf, p. 74

$\mathrm{Na}$ realidade, o custo por habitante é melhor obtido subtraindo-se as receitas do Poder Judiciário, que foram de $\mathrm{R} \$ 13,1$ bilhões em 2019, resultando num déficit de $\mathrm{R} \$ 87,1$ bilhões. Esse número, dividido pela população brasileira estimada pelo IBGE de duzentos e onze milhões em 2019, resulta numa despesa de $\mathrm{R} \$ 412,80$ por cada cidadão. Em outras palavras, cada brasileiro paga pelo Poder Judiciário $\mathrm{R} \$ 412,80$ anualmente quer ele tenha utilizado o Poder Judiciário ou não, além de eventuais taxas judiciais que venha a efetivamente pagar caso tenha alguma demanda. 
Figura 4: Série histórica das despesas

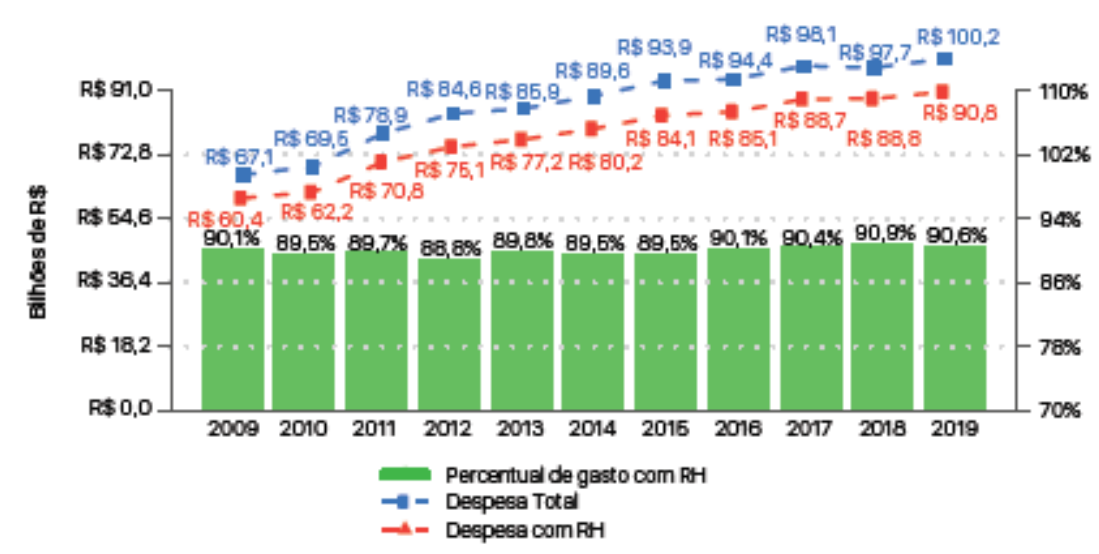

Fonte: CNJ. Relatório Justiça em Números 2020. Disponível em: https://www.cnj.jus.br/wpcontent/uploads/2019/08/b60a659e5d5cb79337945c1dd137496c.pdf, p. 81

Apesar do crescente aumento do custo total da Justiça brasileira, o número de processos pendentes não diminuiu entre 2009 e 2019, mas, ao contrário, cresceu. Ao final de 2019, eram 77,1 mihões de processos pendentes, ao passo que em 2009 eram 60,7 milhões. Isso representa um acréscimo de cerca de 27\%. Felizmente, entre 2016 e 2019, houve a diminuição desse total, que havia alcançado 79,9 milhões, reduziu para 79,5 milhòes em 2017, para 78,6 milhões em 2018 e, finalmente,para 77,1 milhões em 2019, o que representou uma queda de cerca de 3,5\% em três anos, ao passo que, no mesmo período, houve um aumento nas despesas de cerca de $6,1 \%$. 
Figura 5: Série histórica de casos pendentes

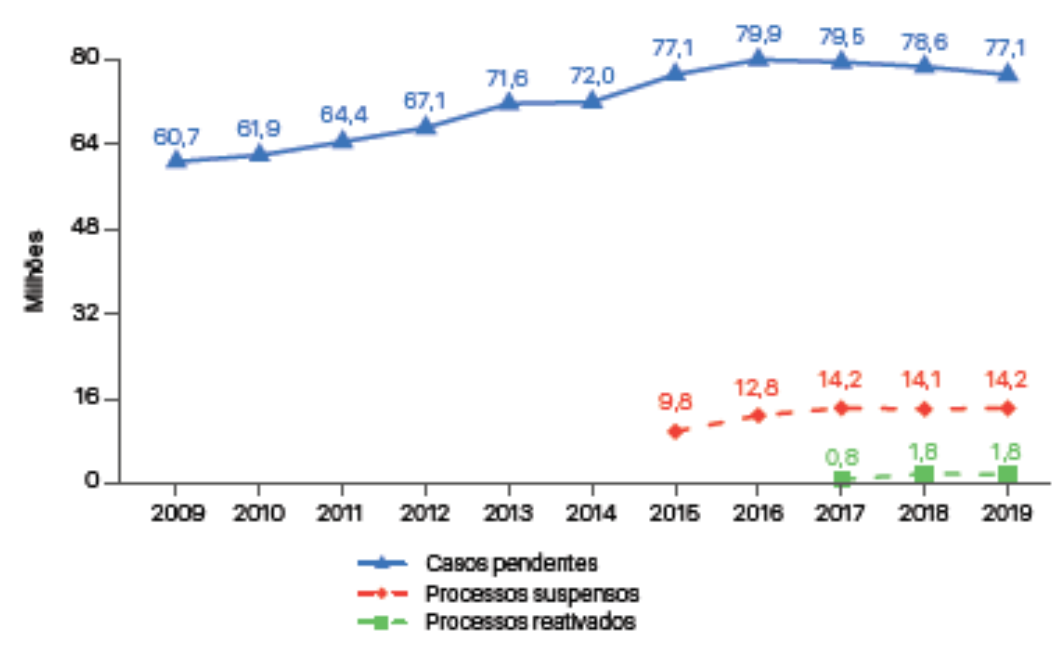

Fonte: CNJ. Relatório Justiça em Números 2020. Disponível em: https://www.cnj.jus.br/wpcontent/uploads/2019/08/b60a659e5d5cb79337945c1dd137496c.pdf, p. 95

Como já se disse, é extremamente preocupante um aumento anual médio de 3,9\% em valores já deflacionados pelo IPCA, sendo, portanto, um crescimento real da ordem de quase quatro por cento ao ano. Além disso, as receitas ${ }^{4}$ arrecadadas pelo Poder Judiciário são sempre insuficientes para cobrir as despesas. Isso é o que está claro no relatório de 2020,

4 O Conselho Nacional de Justiça inclui nessa dotação os tributos recolhidos para Estados e Municípios em virtude de processos judiciais, como os valores de ITCMDs e demais quantias arrecadadas para as fazendas públicas, e não somente as custas judiciais que são as taxas que deveriam remunerar os serviços. Em tese não se tratam de receitas do Poder Judiciário mas de receitas públicas obtidas por meio da máquina judicial. 
referente aos indicadores do Poder Judiciário no ano de 2019 (CNJ,2020, p. 78). Veja o gráfico a seguir ${ }^{5}$ :

Figura 6: Série Histórica das arrecadações

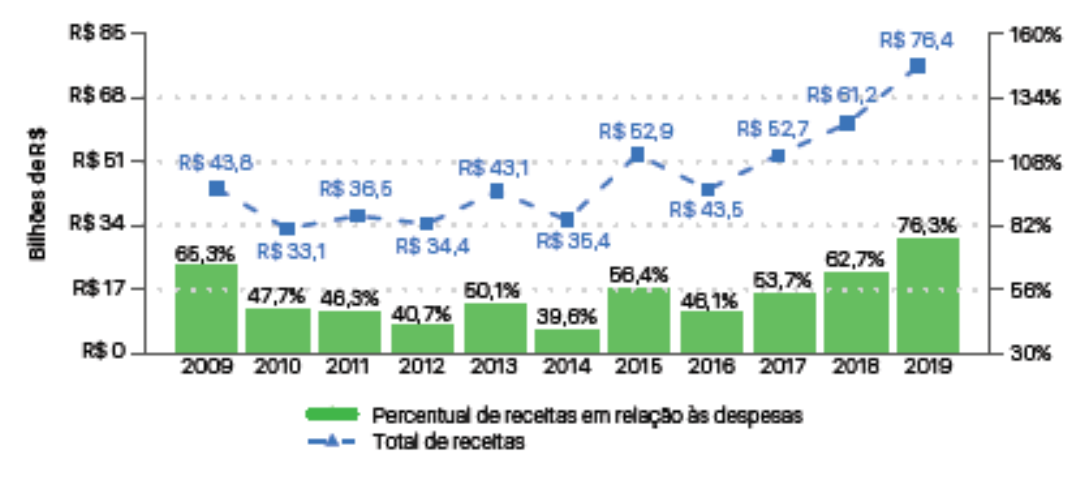

Fonte: CNJ. Relatório Justiça em Números 2020. Disponível em: https://www.cnj.jus.br/wpcontent/uploads/2019/08/b60a659e5d5cb79337945c1dd137496c.pdf, p. 78

Esses dados demonstram a importância de, para se avaliar o custo, não observar somente os valores cobrados como taxas judiciárias, mas o valor efetivamente despendido pela sociedade, que é aquele constante dos orçamentos públicos. A concessão de justiça gratuita para uma das partes não torna todo o processo imune a custos, mas, ao contrário, significa que toda a sociedade terá que arcar com essa despesa e não somente quem provocou o Poder Judiciário ou, eventualmente, o vencido.

\section{DAS EXPERIÊNCIAS DE EXTRAJUDICIALIZAÇÃO}


Conforme D’AMBROSIO (2018), o protesto de certidões de dívidas ativas da PGFN, no período de março/2013 a outubro/2015, resultou na recuperação de 19,2\% daquilo que foi cobrado, percentual bem superior ao recuperado por meio judicial em período menor e sem custo algum para o Poder Público.

Isso demonstra que o protesto de certidões de dívidas ativas pelos tabelionatos de protesto tem sido instrumento muito mais célere e eficaz de cobrança dos créditos fazendários, sem que o ente público tenha de desembolsar qualquer valor para remunerar as serventias extrajudiciais.

O exemplo talvez mais célebre de delegação de funções antes restritas ao Poder Judiciário a notários e registradores foi aquele implementado pela Lei 11.441/2007, que demonstrou ter sido um grande instrumento para a redução do tempo necessário para a realização de inventários, partilhas, separações e divórcios. O inventário extrajudicial, que no âmbito do Judiciário poderia demandar de meses a anos, pode ser realizado no mesmo dia, uma vez pagos os tributos e apresentada a documentação necessária. Dados obtidos junto à CENSEC - Central Notarial de Serviços Eletrônicos Compartilhados - indicam que foram realizados mais um milhão e meio de escrituras referentes a tais atos em dez anos de aplicação da Lei 11.441/2007 (SINOREG, 2018, p. 58).

No Projeto de Lei 6204 de 2019, de autoria da Senadora Soraya Thronicke ${ }^{6}$, vários atos do processo de execução seriam desempenhados pelo tabelião de protesto, o que significaria, conforme disposto na justificativa do projeto, uma economia de mais de sessenta

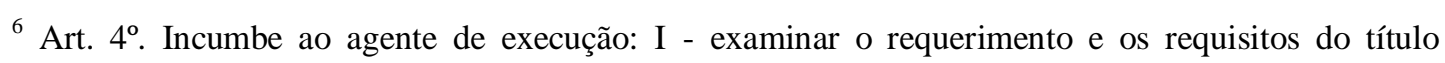
executivo, bem como eventual ocorrência de prescrição e decadência; II - consultar a base de dados mínima obrigatória, nos termos do art. 29, para localização do devedor e de seu patrimônio; SF/19761.96905-01 Gabinete da Senadora Soraya Thronicke III - efetuar a citação do executado para pagamento do título, com os acréscimos legais; IV - efetuar a penhora e a avaliação dos bens; V - realizar atos de expropriação; VI - realizar o pagamento ao exequente; VII - extinguir a execução; VIII - suspender a execução diante da ausência de bens suficientes para a satisfação do crédito; IX - consultar o juízo competente para sanar dúvida relevante; X encaminhar ao juízo competente as dúvidas suscitadas pelas partes ou terceiros em casos de decisões não reconsideradas. $\S 1^{\circ}$ A realização e a comunicação de atos executivos serão de responsabilidade dos agentes de execução, que se submeterão às regras de cooperação institucional entre os tabelionatos de protesto. 
e cinco bilhões de reais, considerando um custo médio de cinco mil reais por processo de execução, custo esse compatível com o apurado por CUNHA, KLIN E PESSOA (2011), de $\mathrm{R} \$ 5.606,67$.

\section{CONCLUSÃO}

Parece ser inquestionável que a efetividade da justiça precisa ser aumentada com a redução dos prazos processuais e a redução do seu custo. Não se vislumbra uma sociedade em que seja negado ao cidadão a possibilidade de ele obter do Poder judiciário o reconhecimento, a reparação ou a cessação da violação de um direito subjetivo de forma efetiva.

Todavia, a prestação jurisdicional está claramente vivendo momento de grave crise. Não somente os prazos para o encerramento de um processo judicial estão aumentando a cada ano, como demonstram os relatórios anuais denominados "Justiça em Números" do Conselho Nacional de Justiça, como os mesmos relatórios apresentam um aumento real crescente do custo do Poder Judiciário, que nossa economia com seguidos déficits públicos não possui capacidade de absorver.

O uso da extrajudicialização de procedimentos processuais tem demonstrado ser eficiente tanto para a redução de prazos como para a minoração de custos. As medidas adotadas até o momento incentivam a busca de outras formas de delegação às serventias extrajudiciais de atos e procedimentos judiciais, como a execução de sentenças e as intimações.

Necessário que se faça, entretanto, o estudo de quais procedimentos poderiam ser delegados e de quais normas deveriam reger essa forma de delegação, pois os caracteres da prestação do serviço privado notarial e registral são diferentes do poder jurisdicional de magistrados.

O Projeto de Lei 6204 de 2019, de autoria da Senadora Soraya Thronicke, parece ser exemplo de algumas das atribuições que poderiam ser delegadas aos serviços extrajudiciais contribuindo para a celeridade processual e a redução de custos do Poder Judiciário. 


\section{REFERÊNCIAS}

\section{BRASIL. Constituição da República Federativa do Brasil de 1988.}

Lei 11.441 de 2007. “Altera dispositivos da Lei no 5.869, de 11 de janeiro de 1973 Código de Processo Civil, possibilitando a realização de inventário, partilha, separação consensual e divórcio consensual por via administrativa.".

CONSELHO NACIONAL DE JUSTIÇA. Justiça em números: indicadores do Poder Judiciário. Disponível em: <https://www.cnj.jus.br/pesquisas-judiciarias/justica-emnumeros/ >. Acesso em: 20 ago 2021.

Cunha, Alexandre dos Santos; Klin, Isabela do Valle; e Pessoa, Olívia Alves Gomes. Nota Técnica Custo e tempo do processo de execução fiscal promovido pela Procuradoria Geral da Fazenda Nacional. Ipea - Instituto de Pesquisa Econômica Aplicada. Brasília, 2011.

D’AMBROSIO, Renata Gontijo. Protesto de CDAs possui taxa de recuperação de $19 \%$. Disponível em: <http://www.pgfn.fazenda.gov.br/noticias carrossel/protesto-de-cdas-possuitaxa-de-recuperacao-de-19>. Acesso em: 31 jul. 2021.

DA ROS, Luciano. O Custo da Justiça no Brasil: uma análise comparativa exploratória. Newsletter. Observatório de Elites Políticas e Sociais do Brasil. NUSP/UFPR, v.2, p. 1-15, 2015.

LAZARI, João Batista; SAVARIS, José Antônio; e PORENA, Daniele. O ACESSO À JUSTIÇA NOS JUIZADOS ESPECIAIS: uma análise crítico-propositiva ao modelo dos Juizados Especiais Federais para obtenção de um Processo Justo. Revista Novos Estudos Jurídicos - Eletrônica, Vol. 19 - n. 4 - Edição Especial 2014, pág. 1291. Disponível em: <https://siaiap32.univali.br/seer/index.php/nej/article/view/6706>. Acesso em: 20 jan. 2021.

MURAD, Flávia Santos . Protesto de Certidão da Dívida Ativa: Extrajudicialização da Cobrança de Créditos Fiscais como Mecanismo de Acesso à Justiça. Disponível em: <https://sucupira.capes.gov.br/sucupira/public/consultas/coleta/trabalhoConclusao/viewTrabal hoConclusao.jsf?popup=true\&id trabalho=2897197\#> . Acesso em: 11 jan. 2021 
NEVES, Fernando Crespo Queiroz. Execução extrajudicial. PUC - SP: 2016. Disponível em:

<https://sucupira.capes.gov.br/sucupira/public/consultas/coleta/trabalhoConclusao/viewTrabal hoConclusao.jsf?popup=true\&id_trabalho=3621377\#>. Acesso em: 14 set. 2021.

RIBEIRO, Flávia Pereira. Desjudicialização da Execução Civil. São Paulo: Pontifícia Universidade Católica de São Paulo, 2012. Disponível em: https://tede2.pucsp.br/handle/handle/5910. Acesso em: 25 jun. 2021.

SANTOS, Boaventura de Sousa, "Introdução à Sociologia da Administração da. Justiça", Revista Crítica de Ciências Sociais, n² 21, pp. 11-37. Coimbra: Universidade de Coimbra, Novembro de 1986.

SINOREGSP. Sucesso comprovado pelas estatísticas marca os dez anos da Lei 11.441. Revista Cartórios com Você, $\mathrm{n}^{\mathrm{o}}$ 6, pp. 58-63. Disponível em: <http://sinoregsp.org.br/revistas/edicao-10>. Acesso em: 13 ago. 2021.

SOUZA, Lígia Arlé Ribeiro de, A importância das serventias extrajudiciais no processo de desjudicialização. Disponível em: 〈http://www.egov.ufsc.br/portal/conteudo/importânciadas-serventias-extrajudicias-no-processo-de-desjudicialização>, acesso em: 18 jul. 2021. 